\title{
A FEBRE COMO MANIFESTAÇÃO CLÍNICA DA TOXOPLASMOSE ADQUIRIDA, FORMA LINFOGLFNDULAR *
}

\author{
Vicente Amato Neto **, Yvone Khairallah de Oliveira e Silva *** \\ e Sélia Reiko Konichi ***
}

\begin{abstract}
Analisaram os autores aspectos relativos à febre em casuistica constituida por 100 pacientes, de ambos os sexos e diversas idades, acometidos de toxoplasmose adquirida, forma linfoglandular. Paralelamente, outras manifestações clinicas da doença foram consideradas.

Como fatos fundamentais apuraram que hipertermia não faz parte, de maneira constante, da configuração clínica da citada modalidade da protozoose. Ela esteve ausente em pelo menos $27 \%$ dos individuos computados no estudo $e$ quando notada, persistiu em geral durante período não superior a um mês e menos do que algumas outras queixas, tendo comumente demonstrado predominios vespertinos.

A constatação referente à fase de permanência das elevações térmicas encerra significado prático, sobretudo na tentativa de elucidação de processo mórbido qualificado como febre de origem indeterminada, pois deve limitar, muitas vezes, interpretações não coerentes com o fato verificado.
\end{abstract}

\section{INTRODUÇÃO}

A importância médica da toxoplasmose é atualmente indiscutivel. Depois da fase na qual vários pesquisadores anteviram o expressivo significado dessa protozoose em termos práticos e recomendaram que ela fosse encarada como bastante digna de atenção, muitos acometimentos devidos ao Toxoplasma gondii puderam ser categoricamente reconhecidos e, para tanto, contribuiu de forma decisiva a disponibilidade, em múltiplos ambientes, de provas sorológicas efetivas e eficientes.

Com o passar do tempo, as implicaçōes clínicas da parasitose em apreço tornaram-se melhor conhecidas, se bem que, acreditamos, ainda seja necessário coletar in- formações a respeito, para que configuração das repercussões orgânicas dela dependentes fique estabelecida em caráter mais definitivo.

Agora, sabemos que a meningoencefalite, erupção cutânea, lesões oculares, miocardite, miosite, hepatite, pneumonia intersticial e provável comprometimento reumatismal ocorrem, isolada ou associadamente, no decurso da modalidade adquirida da infecção, que começou a ser melhor analisada depois de bem identificado o tipo congênito. Essa variedade que não depende obrigatoriamente da participação materna é formada também pelas evoluçōes oligo ou assintomáticas e pelo coniunto, comumente identificado, de manifestações mononucleose "simile", represen-

* Trabalho do Serviço de Doenças Transmissivels, do Hospltal do Servidor Público Estadual "Francisco Morato de Olivelra", de São Paulo (Diretor: Prof. Vicente Amato Neto).

** Diretor do Serviço de Doenças Transmissiveis.

* * Médica do Serviço de Doenças Transmissiveis.

Recebido para publicaçăo em 11.4.73. 
tado pela agressão qualificada como linfoglandular e composta, em especial, por enfartamento de gânglios e linfocitose com células atípicas, ao lado por vezes de diversos sintomas e sinais.

É lógico que se torne imprescindivel, no momento e futuramente, coletar detalhes sobre as maneiras segundo as quais o processo mórbido tem lugar, sobretudo para facilitar os reconhecimentos etiológicos, concedendo a eles segurança, como ainda para evitar confusões, já que elevados teores de anticorpos chegam a ser detectados no soro, até mesmo persistentemente, gerando oportunidades para interpretações inadequadas em face ao citado decurso inaparente.

Como a febre é queixa preocupante e destacada relativamente às afecçōes que a motivam, levando em conta a conveniência de ordem científica anteriormente referida, julgamos útil e oportuno apurar fatos a ela pertinentes e notados à observação de pessoas com toxoplasmose adquirida, abordando paralelamente outros elementos coletados nessa apreciação e valiosos, sem dúvida, em tarefas assistenciais rotineiras.

\section{MATERIAL E MÉTODOS}

Analisamos os prontuários de 100 indivíduos atendidos no Serviço de Doenças Transmissiveis, do Hospital do Servidor Púbiico Estadual "Francisco Morato de Oliveira", de São Paulo. A avaliação, retrospectiva e independente de terapêuticas específicas instituídas, não teve base na consulta e fichas previamente elaboradas. Os doentes procuraram o Ambulatório da instituição e nele estiveram posteriormente internados, em face a intuitos quase sempre de ordens predominantemente cientificas, de agosto de 1964 a janeiro de 1969.

O diagnóstico da toxoplasmose decorreu de indubitável mudança dos resultados de exames sorológicos e, mais precisamente, do teste de Sabin-Feldman e da reação de imunofluorescência indireta, praticados conforme indicou Camargo (2) e que de negativos passaram a positivos, atingindo números aceitos como taxativos. Encontrou apoio, identicamente, em valores iguais ou superiores a $1 / 4.000$ e 1/8.000, respectivamente, quanto às duas provas em questão, excluídas anormalidades quase que com certeza não atribuiveis à entidade em foco.

Sessenta e quatro componentes da casuística eram do sexo masculino e 36 do feminino; no que concerne às idades, expressas em anos, verificamos a seguinte distribuição: 33,26 e 16 , até 10,20 e 30 ; 26 superiores a 30 . Aumento de volume de gânglios linfáticos compunha sempre a situação clínica, fornecendo uniformidade ao agrupamento que decidimos retratar em particular quanto à hipertermia.

Os períodos de tempo decorridos entre o início da tentativa de definição etiológica e a deliberação final variaram segundo os empenhos dos médicos e dos doentes, de insistências ligadas às situações particulares e de disponíbilidades de recursos laboratoriais, como é fácil compreender; entretanto, açeditamos ser judicioso especificá-los: indeterminado - 13; de até 2,45 e 60 dias $-41,31$ e 6 ; de dois a quatro meses -9 .

A ida ao Hospital com o interesse de obter assistência sucedeu em épocas inconstantes após o início dos distúrbios, estando adiante anotadas as fases que se passaram: desconhecida ou estabelecida sem segurança - 17;; de até 10,20 e 30 dias - 45, 13 e 4; superior a um mês - 21 .

Quando a investigação etiológica estava em andamonto, identificamos enfermidades associadas, que inclusive haviam sucedido pouco antes do começo das implicações de natureza toxoplasmótica ou surgiram paralelamente a elas. Detalhadamente, reconhecemos as em prosseguimento anotadas, com os númoros de pessoas correspondentes: cisto ovariano à esquerda - 1; doença difusa do tecido conectivo, não definida, - 1; febre paratifóide - 1; febre reumática - 1; hepatite por vírus A - 1; l'nfoma - 1; sarampo - 5; septicemia estafilocócica - 1; síndrome miastênico — 1; rubéola - 1; tuberculose pulmonar -1 .

\section{RESULTADOS}

Nos Quadros I, II, III, IV, V e VI registramos os dados referentes à febre e a importantes sinais e sintomas que compuseram o quadro clínico nas 100 pessoas consideradas.

Como complementação do que os Quadros I, II, III, IV, V e VI estāo mostrando, é necessário referir que a febre mais 
QUADRO I

A febre como manifestação clínica da toxoplasmose adquirida, forma linfoglandular: análise global

\begin{tabular}{|c|c|}
\hline Febre & $\begin{array}{c}\text { Números } \\
\text { de } \\
\text { pacientes }\end{array}$ \\
\hline 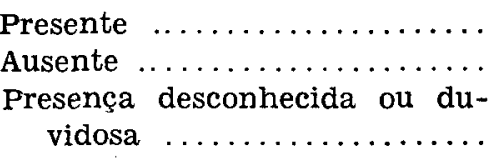 & $\begin{array}{l}61 \\
27 \\
12\end{array}$ \\
\hline Total & 100 \\
\hline
\end{tabular}

QUADRO II

A febre como manifestação clínica da toxoplasmose adquirida, forma linfoglandular: fases de existência antes da internação hospitalar

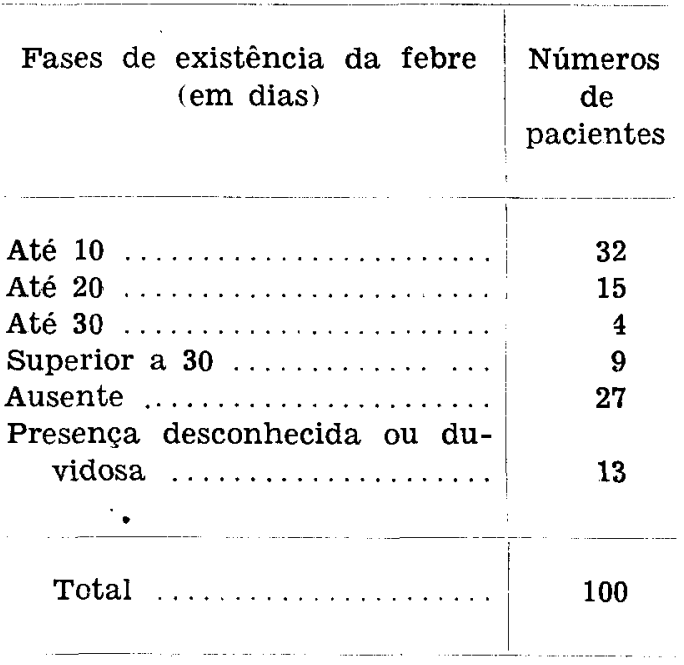

\section{QUADRO III}

A febre como manifestação clínica da toxoplasmose adquirida, forma linfoglandular: fases de existência após a internação hospitalar

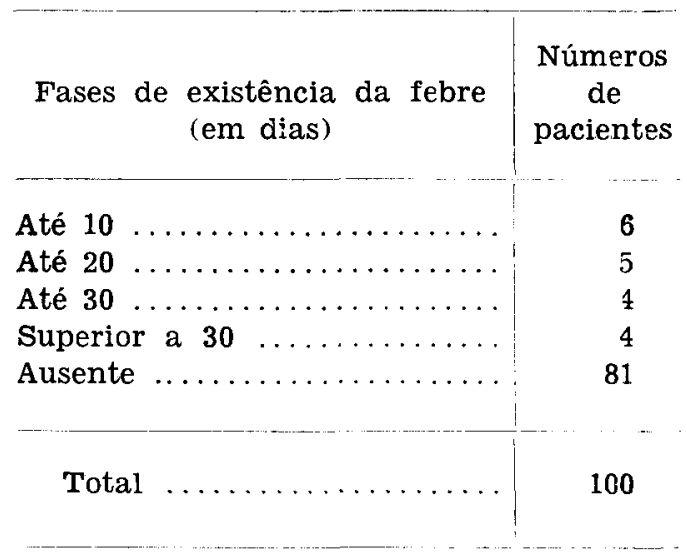

\section{QUADRO IV}

A febre como manifestação clínica da toxoplasmose adquirida, forma linfoglandular: fases que decorreram entre o início da anormalidade e a realização do diagnóstico

\begin{tabular}{l|l} 
Duração das fases rem dias) & $\begin{array}{c}\text { Números } \\
\text { de } \\
\text { pacientes }\end{array}$
\end{tabular}

Até 15 5

Até $45 \ldots \ldots \ldots \ldots \ldots \ldots \ldots \ldots$

Até $75 \ldots \ldots \ldots \ldots \ldots \ldots \ldots$

Até $120 \ldots \ldots \ldots \ldots \ldots \ldots \ldots \ldots$

Indeterminada $\ldots . . . \ldots \ldots \ldots$, 32 
comumente esteve associada a predominio vespertino, o exantema em geral foi máculo-papular, a espleno e a hepatomegalia quase sempre não ultrapassaram um e dois centímetros, respectivamente, dos rebordos costais, sendo menos habituais aumentos pouco maiores. Houve diagnóstico de coroidite no que diz respeito a dois doentes e congestão e cor oculares chamaram a atenção a propósito de igual quantidade de outros constituintes do grupo estudado.

\section{DISCUSSAO}

As explicações, inclusive numéricas, antes expostas, permitem, acreditamos, consignar os comentários a seguir especificados.

1) A febre nāo compõe sistematicamente a configuração clínica da toxoplasmose adquirida, forma linfoglandular, que pode ser encarada como freqüente entre as demais modalidades conhecidas da protozoose. Esteve ausente em pelo menos 27\% dos pacientes e essa taxa é apreciável, mesmo diante da imperfeição da pesquisa retrospectiva que empreendemos.

\section{QUACRO V}

A febre como manifestação clinica da toxoplasmose adquirida, forma linfoglandular: fases de duração das diferentes queixas

\begin{tabular}{|c|c|}
\hline Duração das fases (em dias) & $\begin{array}{l}\text { Números } \\
\text { de } \\
\text { pacientes }\end{array}$ \\
\hline Até 10 & 7 \\
\hline Atè 20 & 17 \\
\hline Até 30 & 14 \\
\hline Até 40 & 3 \\
\hline Superior a $40 \ldots$ & 31 \\
\hline Ausente $\ldots \ldots \ldots \ldots \ldots$ & 2 \\
\hline Indeterminada $\ldots \ldots \ldots \ldots \ldots$ & 26 \\
\hline
\end{tabular}

Total
2) O período de existência da hipertermia em geral não é superior a um mês e essa constatação precisa ficar enfatizada. Por vezes, à tentativa de esclarecimento da natureza de determinada doença, envolta em dificuldades especiais, caracterizando situação reputada como febre de origem indeterminada, a hipótese de que infecção pelo Toxoplasma gondii figure como responsável surge em cena. A afirmação que registramos limita, porém, as concepções dessa ordem.

3) Duas circunstâncias tornaram - se patentes: o nítido predomínio de elevações térmicas previamente às internações hospitalares, concretizadas muitas vezes quando estavam suplantado estádios mais iniciais e justificadas pelas intenções já apontadas, e a demora sensível, esclarecida no Quadro IV, para definição segura da etiologia. Fatores múltiplos devem, a respeito, ter influido, tais como impressōes subjetivas, escassa disponibilidade de efetivos recursos laboratoriais, remota cogitação do diagnóstico e lentidão para surgir "viragem" sorológica, como Amato Neto (1) já salientou em publicação anterior.

\section{QUADRO VI}

A febre como manifestação clínica da toxoplasmose adquirida, forma linfoglandular: outros importantes sinais e sintomas presentes

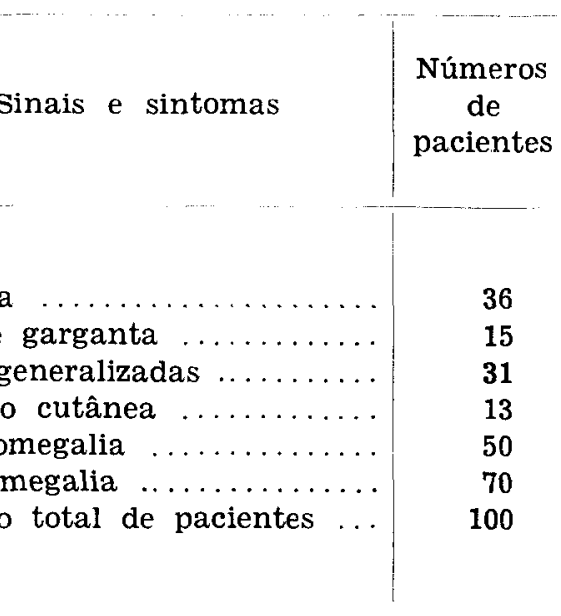


4) A persistência de outras queixas comumente suplantou a da febre e o Quadro $\mathrm{V}$ documenta esse fato, valorizável em trabalhos assistenciais rotineiros.

5) Cefaléia, dores de garganta generalizadas, erupção cutânea, esplenomegalia e hepatomegalia em muitas oportunidades acompanharam a anormalidade da temperatura corporal e sobremodo os dois últ:mos sinais citados delinearam não raramente o tipo linfoglandular da doença. Assim, é lícito rememorar que esses sintomas e alteraçōes semiológicas fazem parte, de forma razoavelmente habitual, de um conjunto de dados que têm a capacidade de conduzir à suspeita de que toxoplasmose adquirida, linfoglandular, deve estar em foco, em deliberações diagnósticas.

6) Talvez investigações prospectivas proporcionem ensinamentos mais aceitáveis e valiosos do que estes que agora anotamos. Entretanto, cremos que, modestamente, coletamos informes orientadores, em terreno que estava necessitando de abordagem na pior das hipóteses preliminar.

Piquet \& cols. (4), com fundamento em 30 observaçōes, ficaram convencidos de que elevações anormais da temperatura corporal não fazem parte do panorama clínico que a toxoplasmose adquirida, de tipo linfoglandular, pode compor. Não endossamos essa opinião e a discordância serve para documentar a validade da intenção que nos conduziu à feitura desta avaliação

7) Os males prévios, associados e paralelos, antes indicados, talvez tenham exercido influências e alterado a total veracidade de nossas deduções, mas nunca de forma global e taxativa, pois recorremos a quantidade de pacientes razoavelmente grande e capaz de atenuar nitidamente essas participações a respeito das conclusões que estabelecemos.

Nesta oportunidade, entretanto, rememoramos o "oportunismo" do Toxoplasma gondii, as confusōes provocadas por erupções cutâneas que tornam-se notadas em virtude da participação do protozoário ou são atribuíveis a doenças exantemáticas e, por fim, acontecimento que médicos vêm notando em tarefas rotineiras, sem conviç̧ão para afirmação categórica e há pouco, porém, enfatizado por Guimarães \& cols. (3) e consubstanciado na possibilidade de modalidade sintomática da parasitose surgir logo após moléstia diversa, como o sarampo, entre outras.

\section{SUMMARY}

In this paper the authors analyze several aspects related to fever in 100 patients, of both sexes and different ages, bearers of acquired toxoplasmosis, lymphadenopathic form. Simultaneously, other clinical manifestations of the disease were considered as well.

As basic finding the authors observed that fever was not at all a constant sign in the clinical picture of the said form of the disease. It was absent in at least $27 \%$ of the studied patients; when present, it lasted in general for a period of time not longer than one month and less than some other symptoms. Usually, fever was higher in the afternoon.

The facts above are of practical importance, and should be taken into account whenever a discussion on differential diagnosis of fever of unknown origin is under consideration. 


\section{REFERÊNCIAS BIBLIOGRÁFICAS}

1. AMATO NETO, V. - Comentários sobre o comportamento da reação de Sabin-Feldman em relação ao diagnóstico e controle de cura da toxoplasmose. Rev. Soc. Brasil. Med. Trop., 1: 231-241, 1967.

2. CAMARGo, M. E. - Estudo comparativo das reações de Sabin-Feldman e de imunofluorescência indireta, para a toxoplasmose, em 1.000 soros humanos. Comportamento anômalo de alguns soros. Tese. Fac. Med. Univ. São Paulo, 1965.
3. GUIMARÃES, J . X., KUSCHNAROFF, T. M., SILVA, L. G. A. \& PESSÔA, M. C. - Surto de toxoplasmose-doença na vigência de doença infecciosa aguda. Apresentado no IX Congresso da Sociedade Brasileira de Medicina Tropical, realizado em Fortaleza, Estado do Ceará, de 4 a 7 de fevereiro de 1973.

4. PIGUET, H., CHRISTOL, D., BILSKIPASQUIER, G . \& BOUSSER, J . - La toxoplasmose ganglionaire acquise de l'adulte (Analyse de 30 observations et revue de la littérature). Sem. Hôp. Paris, 42: 1251-1261, 1966. 